\title{
A IMIAGEIV DA MULHER NA OBRA DE VICTOR HUGO
}

\author{
GUSTAV JAMES SZABO e NAIR DOS SANTOS
}

Nosso objetivo neste trabalho é buscar no romance Les Misérables, de Victor Hugo, a imagem da mulher na pessoa de Fantine como um perfil já esboçado pelo autor em obras anteriores.

As personagens que dominam a efabulação em Les Misérables são dois. Em primeiro lugar vem a personagem masculina Jean Valjean, símbolo do povo oprimido, e em segundo lugar vem Cosette, símbolo do sofrimento da criança pobre. Somente em terceiro lugar aparece Fantine, mãe solteira, símbolo da mulher oprimida.

Tendo morrido cedo no romance, nem por isso deixa ela de ser importante para a demonstração que o autor tenciona fazer, pois sua influência será determinante para o desenvolvimento da história de Jean Valjean e Cosette. Cosette, filha de Fantine, vai viver o sonho das mães pobres: o de realizar um casamento burguês que a torna rica; Jean Valjean, de modo quase imperceptível, vai ser obrigado a assumir o papel da mãe falecida.

A união simbólica das duas figuras, Jean Valjean e Fantine, torna-se evidente, não só porque ele assume o lugar de Fantine na vida de Cosette, mas também pela identidade que encontramos em vários aspectos de suas vidas. Os dois nascem povo, perdem os pais cedo na vida, aceitam ainda muito jovens, de boa graça, a necessidade de trabalhar para sobreviver. Os "crimes" de ambos são cometidos em circunstâncias tão difíceis, que ficam absolvidos, aos olhos do leitor, de qualquer culpa. Castigados, roubados, degradados, esmagados por uma sociedade hostil, ambos se tornam conscientes, embora imperfeitamente, da natureza da injustiça que pesa sobre eles e aprendem a odiar os símbolos de sua opressão (no caso de Fantine, ironicamente, o próprio Jean Valjean, disfarçado em M. Madeleine, capitalista e prefeito de Montreuil-sur-mer). Ambos são salvos por seus opressores e se dedicam à felicidade de Cosette, suportando grandes sofrimentos. Ambos adoecem e definham em conseqüência de sua dedicação, e ambos são atendidos por médicos que reconhecem que a chegada de Cosette poderia salvar a vida do paciente. Ambos morrem depois de um lento declínio físico, em que, para acentuar o paralelo, Hugo torna velha a jovem Fantine.1 Antes

Gustay James Szabo e Nair dos Santos são professores da Universidade Federal de Viçoça (MG)

ILe mal physique avait complété l'oeuvre du mal moral. Cette créature de vingt-cing ans avait le front ridé, les joues flatques, les narines princées, les dents déchausées, le teint plombé, to cou osseux, len davieules aaillantes, les membres chétifs, la peau terreuse, et get eheveux blond pounalent méló de deveux gris. HélasI comme la maladie improvise li vielitessel HUGO, Vietar, Les Mindrables Ed. Marius - François Guyard. Paris, Gasnies, 1963, y, L, 0.306 
de morrer, ambos têm consciência da iminência da morte, reluzem com um fulgor espiritual que pressagia a felicidade eterna da alma, têm visões, tornamse de repente tagarelas e recebem a visita da bem amada Cosette (no caso de Fantine, por um engano que a faz julgar a filha presente). Depois da morte, a luz celestial que os envolve, e, finalmente, o anonimato do túmulo.

Diante de tantas similaridades que unem Jean Valjean e Fantine como símbolos do povo, resta destacar a especificidade da imagem de Fantine que, como mencionamos, é a culminação de uma lenta evolução na obra do autor.

Começando com o drama Marion de Lorme (1829), Victor Hugo era sem dúvida o principal expoente da idéia romântica de que a sociedade é a grande culpada da condição da mulher decaída. Nessa peça, a simpatia pela cortesã é garantida pelo inesperadamente genuíno e, conseqüentemente, puro amor que ela tem por Didier, e também, de modo paradoxal, pela impossibilidade de realizá-lo. Hugo joga com o conflito subliminar no desejo de seu público de ver uma pecadora castigada e de ver o amor de uma heroína "pura" realizado, e soluciona o conflito com um ato de decapitação que salienta a impossibilidade da proposição romântica

Em Lucrèce Borgia (1833), a heroína é demasiadamente malvada para ganhar inteiramente a simpatia do público e, de fato, não pode ser considerada uma mulher decaída no mesmo sentido que Marion de Lorme. No entanto, seu exemplo é relevante pelo fato de ela sofrer e, eventualmente, morrer em conseqüência de seu amor materno não correspondido.

A figura de Jane Talbot na peça Marie Tudor (1833) é interessante porque ela não só "cai", mas é também "redimida" com sucesso. Seduzida por Fabiani, que é também o amante da rainha, ela culpa sua pobreza e sua natureza frívola por sua queda. Felizmente para Jane, o artesão Gilbert, que a ama, está pronto a ser indulgente, enquanto ela, sem saber que é filha de Lord Talbot, só aspira a ser "mulher do operário Gilbert" e a lutar contra a injustiça social. O que importa para o nosso estudo é a ligação da reabilitação da mulher decaída com a virtude e a resistência do povo.

Em Angelo (1835) a cortesã Tisbe declara que prostitutas como ela não são inferiores a mulheres consideradas virtuosas pela sociedade. 2 No prefácio da peça, o autor afirma que Catarina, "mulher da sociedade", é vítima como Tisbe, "mulher fora da sociedade." De fato, ele apaga inteiramente a distinção entre as duas ao falar de "dois tipos vivos, todas as mulheres, toda a mulher" 3 e coloca a culpa da condicão da mulher, não na mulher, mas no homem e na espécie de sociedade criada pelo homem. 4

Hugo foi o único dramaturgo importante de seu tempo a defender a cortesã contra a sociedade, $\overline{5}$ e não limitou sua defesa apenas ao drama. 0

$2 \mathrm{Et}$ vous ne valez pas mieux que nous, Mesdames! Ce que nous disons tout haut à un homme en plein jour, vous le balbutiez honteusement la nuit.... Non, pardieu! vous ne nous valez pas! Nous ne trompons personne, nous! Vous, vous trompez tout le monde.. nous valez pas! Nous ne tromplet. Eds. J.-J. Thierry e Josette Mélèze. Paris, Pléiade, 1963-1964. V. II, p. 612.

3ibid.p. 555 .

4"Rendre la faute à qui est la faute, c'est-à-dire à l'homme, qui est fort, et au fait social, qui est absurde". Ibid. p.555.

"Courtisane" in the French theatre from Ilugo to Becque (1831-1885). Baltimore Maryland, The Jdin Hopkins Press, 1947 curto poema lírico "Oh! nunca insulte a mulher que cai" (Les chants du crépuscule, XIV), escrito no mesrno ano que Angelo, não só sintetizou as idéias de Hugo quanto à prostituta, como também delineou um cenário para sua representação: esmagada pelo peso da sociedade e instigada pela fome, ela é retratada como uma criatura virtuosa dominada pelas circunstâncias. Hugo culpa a si mesmo, ao leitor, a todos os homens, e especialmente os ricos, pela situação angustiante da mulher decaída:

A culpa está em nós; em ti, rico! em teu ouro!

O poema termina com a afirmação de que o amor pode redimi-la:

Para que a gota d'água saia da poeira,

E volte a ser pérola em seu primeiro esplendor

Basta, e e assim que tudo volta ao dia,

m raio de amor!6

Num poema mais realista e mais longo, "Melancholia" (Les contemplations, Livro 30, II), reconhecido pelo próprio Hugo como germe de Les Misérables, 7 uma órfã de 17 anos luta para sobreviver, mas perde, no frio do inverno, seus pertences, seu emprego, sua saúde, sua honra, sua virtude e respeito de si mesma. Alvo de zombarias na rua, ela canta e ri para esconder sua vergonha. Esses detalhes deveriam ser repetidos em Les Misérables.

Na história do romance francês, o protótipo da mulher decaída, a personagem Manon Lescaut, do romance do mesmo nome, da autoria de Prévost, não é nem muito bom nem muito mau, mas simplesmente amoral. 8 Paquette la Chantfleurie, mãe da Esmeralda de Notre-Dame de Paris, romance gótico de Victor Hugo, prenuncia, em vários aspectos, a figura de Fantine, mãe de Cosette em Les Misérables, ${ }^{9}$ sem contudo se destacar como prostituta virtuosa. A ausência dessa característica nessa personagem de Hugo é realmente curiosa pelo fato de que foi criada na mesma época da concepção de Marion de Lorme (1828-31), que no entanto recebe do autor os traços da virtuosidade mesclada à prostituiç̃o. O que separa Fantine e Paquette é uma concepção totalmente diferente da importância simbólica central de cada uma delas. Enquanto Fantine se destina a ser a demonstração viva do tratamento iníquo dado pela sociedade à mulher, a figura mais antiga de Paquette é, antes de tudo, agente e vítima da força cega do destino que destrói sua filha.

O romance - reportagem Claude Gueux, que apareceu em mais de uma versão (1832-1834), ofereceu a Hugo a oportunidade, que ele não aproveitou, de incluir a figura da prostituta, pois havia uma na vida do personagem histórico de Claude Gueux. Seu nome era Eulalie Lelong. Ela recebeu do condenado uma herança insignificante de 10 francos. 10 Mas a obra polêmi-

6HUGO, Victor. Oeuvres poétiques. Ed. Pierre Albouy. Paris, Pléiade, 1967. V. I, p. $858-9$

7Ibid. V. II, p. 1458

8BRAUN, Sidney D, The "Courtisane"... p.19-21.

9A semelhança entre as duas figuras não escapou aos críticos contemporâneos. Assim que fot publicadn a primerin parte de Les Misérables, Louis Veuillot escreveu sobre que Tor "Antes do momento em que Valiean a contra nós já a conot escreveu sobre

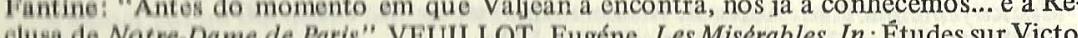
Tha de. Paris Société Générale de Librairie Catholique. 1986. p. 269.

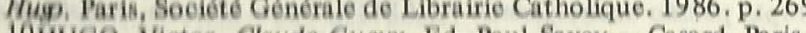

Press Universitaires de Franee, 1956 nota $115,0.36$ 
ca de Hugo exigia um herói imaculado,11 e a prostituta foi eliminada da história.

No entanto, ao sumariar Claude Gueux, Hugo colocou o problema da redenção da prostituta no mesmo nível do de salvar o condenado: "Tende piedade do povo, de quem a prisão toma os filhos, e o lupanar as filhas. Tendes forçados em demasia, tendes prostitutas em demasia".12

Quando Hugo finalmente incluiu a prostituta como figura proeminente no romance, estava seguindo o caminho de escritores célebres como Georges Sand, Balzac e Eugène Sue (sem falar de figuras literárias menos conhecidas, como Paul de Kock e Jules Janin). Num curto prefácio a Les Misérables, Hugo anuncia que a condição da mulher na sociedade é um de três problemas de que se preocupa o romance. 13 Causa e efeito recebem a simplicidade de um "slogan": "A decadência da mulher pela fome".14 Esta simplicidade permite a Hugo dramatizar a prostituta como exclusivamente vítima da fome. A queda de Fantine foi o resultado de fomes gêmeas: a fome do alimento e a fome do amor. 15

Dentro da tônica geral do romance, que trata da condição dos humildes na sociedade, e fazendo parte do universo feminino da obra, que focaliza unicamente mulheres pobres e sofredoras, Fantine encarna a figura da mulher tradicional que, em parte, sobrevive ainda nos dias atuais. É a mulher dominada pela mística feminina, 16 que a faz aspirar ao casamento e à maternidade como fatores imprescindíveis na sua vida e até como condições essenciais da feminilidade. Nesse contexto, a dupla fome de que é vítima a nossa heroín vai colocar em evidência a figura masculina, na pessoa de seu namorado amante, Tholomyès, que, como seus companheiros de diversão, aparecem no romance para personificar o homem na civilização masculina, aquele que cria os valores da sociedade e detém uma forma de poder que the permite utilizar a mulher como um objeto descartável. A fala transcrita no bilhete dos namorados endereçado a Fantine e suas amigas no momento em que as abandonam, bem coloca a supremacia do homem que, além do amor, deve ocupar outros espaços sociais, diferentemente da mulher: "Nós retornamos à sociedade, ao dever e à ordem "17 E nessa supremacia do poder exercido pelo homem coloca-se também a questão do duplo padrão de moralidade, 18 segundo o qual o homem nunca é atingido e é sempre perdoado pelos seus erros, o mes mo não acontecendo com a mulher. Enquanto Tholomyès desaparece da vida de Fantine para reintegrar-se à sociedade, livre e desimpedido, ela inicia um processo de sofrimento e decadência, acusada de fatos cuja responsabilidade

11 Ibid.p.58, para as opiniões de Savey-Casard sobre as necessidades internas do romance reportagem de Hugo.

12 Ibid.p.123

13HUGO, Victor - Les Misérables ... V. I, p.3

14 Para o homem, o paralelo da decadência é a degradação; para a fome é o proletariado. Para a criança, os termos sãol atrofia e a noite (Ibid.)

15 Ibid. p.156

16Para análise mais completa da expressão "mística feminina" ver FRIEDAN, Betty. Mística feminina.Trad. Áurea B. Weissemberg. Petrópolis, Vozes, 1971

17 HUGO, Victor. Les Misérables ... V. I, p.182.

18 Para análise desse duplo padrão de moralidade ver LEITE, Dante Moreira. Psicologia e literatura . 2ed. São Paulo, Companhia Editora Nacional, p.159 deveria recair também sobre ele. Fantine é ainda vítima desse duplo padrão de moralidade quando é brutalizada pela polícia que toma a defesa de seu agressor, por se tratár de um homem e sobretudo burguês.

A dimensão quase trágica da vida da heroína começa a se desencadear a partir do momento em que vê frustrada a sua aspiração a um modelo tradicional de felicidade da mulher, baseada na proteção do homem, e, tendo de trabalhar para a própria subsistência, não consegue um trabalho bem remunerado pelo fato de ser mulher. Esse trabalho, perfeitamente adequado ao modelo da mística feminina, embora buscado como forma de sobrevivência, não a impediu de cair, em conseqüência da baixa remuneração, oriunda do próprio tipo de trabalho, das dificuldades do mercado e da exploração de terceiros:

Trabalhava dezessete horas por dia: mas um arrematante do trabalho das prisões que fazia as prisioneiras trabalharem por menos fez os preços baixarem de repente, o que reduziu o salário das costureiras livres a nove soldos. Dezessete horas de trabalho a nove soldos por dia! 19

A insuficiência do trabalho feminino como meio de sobrevivência fica patente na história de Fantine porque, num primeio momento de sua vida apesar do trabalho, não pode dispensar a proteção de Tholomyès que, além de socorrê-la na fome do amor, ajuda a mitigar a sua fome de alimento; e num segundo momento, sem a proteção do homem que amava, recrudesce a sua fome de alimento diante dos rigores do inverno, e acaba se prostituindo para poder desempenhar o seu papel de mãe protetora.

Georges Piroué, provavelmente consciente da diferença existente entre os dois tipos de fome de que se torna vítima a nossa heroína, pronuncia uma sentença bastante severa: "Não há nenhuma dúvida de que Fantine seja em primeiro lugar um ventre, seja ela decaída ou sublime. Ela se deu, depois se vende". 20 Gilette Ziegler vê no próprio Hugo uma atitude de conivência com seu século por condenar as mulheres que se afastam do caminho sexual con vencional. $21 \mathrm{Na}$ verdade, quando Fantine se entrega a Tholomyès, Hugo se refere a ela como uma moça honesta. Como suas colegas, conservava "essa flor da honestidade que na mulher sobrevive à primeira queda". 22 No segundo momento de sua decadência, após ser abandonada por Tholomyès, Hugo assim se pronuncia a respeito das pressões e maus tratos exercidos pelos credores sobre Fantine, que, como vimos, cumpria uma jornada de dezessete horas de trabalho por dia:

Que queriam dela, meu Deus

Ela se sentia encurralada e desenvolvia-se nela alguma coisa de animal

feroz.

E a desventurada fez-se prostituta. 23

19HUGO, Victor. Les Miserábles... V. I, p.231.

20 PIROUE, Georges. Victor Hugo romancier ou les Dessus de l'inconnu. Paris, Denoël,

1964. p.69.
21 Victor Hugo, "lui aussi, est de son temps: il blâme, tout en l'excusant, cette chute, et n'admet pas qu'une jeune fille puisse disposer sans remords de son corps". ZIEGLER, Gilette. Fantine, Cosette, Eponine... Europe, XL (394-395): 158. fev.-mar., 1962

22.HUGO, Vietor, Les Miserabels... v, 1, p, 154

23HUGO, Vietor, Les Misdrbles ... p. 231 ? 
Não se pode dizer que essa maneira de se referir aos fatos possa constituir por parte de Hugo algo que se deva entender como uma condenação. Pelo contrário, o encadeamento dos episódios da narrativa nos oferece elementos através dos quais podemos concluir que a prostituição de Fantine se dá em conseqüência de fatores altamente determinantes como a sua condição econômica insuficiente agravada pela exploração de que foi vítima por parte dos Thénardier, sob os cuidados dos quais se viu obrigada a deixar a filha.

A imagem de Fantine se ergue no romance através de uma seqüência de males e desgraças que recaem sobre ela, partindo da própria sociedade que, depois de fazê-la cair, julga-a com severidade. Tholomyès explorou-lhe o corpo, iludiu-lhe a alma, abandonando-a com uma filha; a Thénardier e o marido, consumindo-lhe todo o dinheiro, obrigaram-na a sacrifícios absurdos; o excesso de horas de trabalho e a baixa remuneração desgastaram-lhe o corpo e a levaram à decadência moral.24 $\hat{E}$ assim que nos momentos finais de sua vida Fantine, ao receber a proteção de Madeleine, representa a figura da mulher como um ser frágil, que năo pode prescindir do apoio do homem, seja ele marido, amante ou simplesmente um protetor.

Mas acima de tudo Fantine encarna na obra o protótipo da mulher tradicional, na qual predomina o sentimento, o que faz com que o sentido de sua existência seja determinado exclusivamente pelo amor que dedicou ao homem que amou como marido e à filha à qual se devotou com o sacrifício da própria vida.

E através de Jean Valjean que o autor concretiza a sua visão a respeito do julgamento da moral de Fantine. Despedida da usina de Madeleine por não ter sido "uma moça direita", ela se torna para ele um objeto de remorso e, mais tarde, uma luz orientadora. Ele passa então a oferecer a Fantine uma proteção total, que inclui o futuro de Cosette. Somente a personalidade superficial de Fantine é conhecida pelos seus detratores, que a vêem apenas através do estereótipo, levados unicamente pela sua vida social. Seus sentimentos reais só vão ser conhecidos por Madeleine, que também é portador de um passado de sofrimentos e por isso mesmo capaz de se tornar sensível aos padecimentos de Fantine. As próprias palavras de Madeleine dirigidas a ela revelam a posição do autor que, contrariamente à lei social, estabelece valores através de uma lei da consciência. “...a senhora nunca deixou de ser virtuosa e santa diante de Deus!25 E, pois, como personificação da sociedade que Jean Valjean admite o erro que cometera e reconhece a superioridade real de Fantine.

Hugo vê a prostituição a que esteve sujeita Fantine como uma forma de escravidão imposta pela sociedade numa "civilização governada por Cristo". A esse respeito, conclui: "Não é esta uma das menores vergonhas para o homem".26

24PARENT-DUCHĀTELET, em sua obra La prostitute dans la Ville de Paris (1836) aponta, entre as causas da prostituição, a impossibilidade das mulheres viverem de seu trabalho por causa dos baixos salários, além da concorrência dos homens, que passaram a exercer funções habitualmente atribuídas a elas. Apud THIBERT, Marguerite, Le Feminisme dans le socialisme français. Paris, Marcel Giard, 1926. p. 105.

25 HUGO, Victor. Les Misérables.... V. I. p. 246

26Ibid. p.232.
Vemos então que, apesar de Fantine ter aparecido na narrativa mais como um motivo que possibilitou a remissão e ascensão de Jean Valjean a fim de concretizar a ideologia moral em que se baseia a obra, a sua figura traça as linhas de uma tese já colocada por Hugo em obras anteriores, em que ele coloca a decadência moral da mulher como obra de uma sociedade cujos valores não foram criados por ela, mas pelo homem.

\section{REFERÊNCIAS BIBLIOGRÁFICAS}

BRAUN, Sidney D. The "Courtisane" in the french theatre from Hugo to Becque (1831-1885). Baltimore/Maryland, The John Hopkins Press, 1947.

FRIEDAN, Betty. Mistica feminina. Trad. Áurea B. Weissenber. Petrópolis, Vozes, 1971.

HUGO, Victor. France, 1956.

Les Misérables. Ed. Marius-Francois Guyard. Paris, Garnier, 1963. 2v.

Les Miserables. Ed. Martus poétiques.

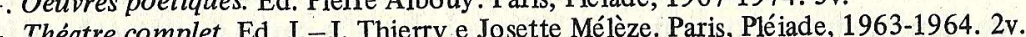
LE, Dante Moreta. Psicologia e literatura 2 ed São Paulo, Companhia Editora cional, 1967.

cional, 1967. . lo/Brasília, Hucitec, 1984 .

lo/Brasília, Hucitec, 1984.

PIROUÉ,
1964.

AFFIOTI, Heleith I.B. . A mulher na sociedade de classes: mito e realidade. 2.ed. Petró polis, Vozes, 1979

SCHENKEL, Susan. $A$ mulher bem sucedida. Trad. Israel Jelin. São Paulo, 1988

THIBERT, Marguerite. ! Le Feminisme dans le socialisme français de 1830 à 1850.। Paris, Marcel Giard, 1926.

VEUILLOT, Eugène. Les Misérables. In de Libraire Catholique, 1886.

ZIEGLER, Gilette. Fantine, Cosette, Eponine... Europe, 40 (394-395): 157-160, fev./ mar., 1962 